Article

\title{
Optimization of a Heliostat Field Layout on Annual Basis Using a Hybrid Algorithm Combining Particle Swarm Optimization Algorithm and Genetic Algorithm
}

\author{
Chao Li ${ }^{(D)}$, Rongrong Zhai * and Yongping Yang \\ School of Energy, Power and Mechanical Engineering, North China Electric Power University, Beijing 102206, \\ China; lichao201408@163.com (C.L.); yypncepu@163.com (Y.Y.) \\ * Correspondence: zhairongrong01@163.com; Tel.: +86-10-61772284
}

Received: 25 October 2017; Accepted: 15 November 2017; Published: 21 November 2017

\begin{abstract}
Of all the renewable power generation technologies, solar tower power system is expected to be the most promising technology that is capable of large-scale electricity production. However, the optimization of heliostat field layout is a complicated process, in which thousands of heliostats have to be considered for any heliostat field optimization process. Therefore, in this paper, in order to optimize the heliostat field to obtain the highest energy collected per unit cost (ECUC), a mathematical model of a heliostat field and a hybrid algorithm combining particle swarm optimization algorithm and genetic algorithm (PSO-GA) are coded in Matlab and the heliostat field in Lhasa is investigated as an example. The results show that, after optimization, the annual efficiency of the heliostat field increases by approximately six percentage points, and the ECUC increases from $12.50 \mathrm{MJ} / \mathrm{USD}$ to 12.97 MJ/USD, increased about 3.8\%. Studies on the key parameters indicate that: for un-optimized filed, ECUC first peaks and then decline with the increase of the number of heliostats in the first row of the field $\left(\mathrm{Nhel}_{1}\right)$. By contrast, for optimized field, ECUC increases with Nhel ${ }_{1}$. What is more, for both the un-optimized and optimized field, ECUC increases with tower height and decreases with the cost of heliostat mirror collector.
\end{abstract}

Keywords: solar tower power system; heliostat field optimization; particle swarm optimization algorithm and genetic algorithm (PSO-GA); annual performance

\section{Introduction}

In China, over $60 \%$ of power generated from the coal-fired power plant, which contributes $40 \%$ of total national emissions [1]. What is more, because of the severe pressure from the international community to reduce carbon emissions, China has started to focus on generating power from renewable energy [2]. Of all the renewable energy, solar energy is arguably one of the most favorable solutions for the green power generation and concentrating solar power (CSP) technologies are expected to be the most promising technologies that are capable of large-scale electricity production [3-5]. It is estimated that CSP could meet approximately $11 \%$ of the global demand for electricity by 2050 [5]. Among all of the CSP technologies, named the parabolic trough collector, the linear Fresnel reflector, the parabolic dish system, and the solar tower, the solar tower technology has unique advantages when compared with other CSP technologies, which can provide the greatest potential for high efficiency and scalability [6]. In a solar tower power plant (STPP), solar energy is collected by the heliostat to produce steam to drive electrical generators. From the previous studies $[3,7,8]$, it has found that the heliostat field contributes about $50 \%$ to the total cost and causes power losses by $40 \%$ in STPPs. For this reason, the design and optimization of the heliostat field layout are very important and the heliostat field remains an active research field. 
Several studies have developed various codes and methods, such as HFLCAL [9], MIRVAL [10], DELSOL [11], and Campo [12] to simulate the optical efficiency of a heliostat field. Because of the high computational cost and variables that are considered for a heliostat field, a major limitation of heliostat layout optimization is computational time. Thus, many attempts have been made to develop methods for a more accurate and faster calculation of the efficiency of the heliostat field. Besarati et al. presented a method to determine the heliostats with the greatest potential for shadowing and blocking a heliostat, which can significantly reduce the computational time [7]. Cádiz et al. proposed a new method that can optimize azimuthal distances between heliostats for a given time to accurately calculate of shadowing and blocking factor [13]. Wei et al. developed a new code for heliostat field layout design, with which the heliostat can be placed with a higher efficiency and a faster response speed of the design and optimization can be obtained $[8,14]$. Kim et al. adopted polygon clipping algorithm in estimating the shadowing and blocking efficiency, which can be as fast as the projection method, and as accurate and as flexible as the discretization method. The presented method has been tested on PS10 heliostat layout with two cases: unconstrained and constrained heliostat field area. Results show that both cases result in an equal improvement of $0.6 \%$, while the heliostat field area is reduced by $3.4 \%$ for constrained and is increased by $1.8 \%$ for unconstrained [15].

On the other hand, some authors focus on the optimization of heliostat field layout to improve its efficiency. Noone et al. developed a new computationally efficient heliostat field layout model. Results indicate that the developed model was able to improve the PS10 efficiency by $0.36 \%$ and to reduce the land area by $15.8 \%$ [16]. Gadalla et al. carried out comparative analyses between two circular heliostat field layouts. The results indicate that the optimum weighted efficiencies for Campo radial-staggered and biomimetic spiral layouts are similar, $61.6 \%$ and $61.5 \%$, respectively [17]. Eddhibi et al. designed and analyzed an efficient heliostat field layout with minimum losses due to the shadowing and blocking effect [18]. However, because of the high complexity of the heliostat field, the optimum design of the heliostat field of STPPs remains a challenge. Therefore, some intelligence algorithms with better global search abilities over conventional optimization algorithms have been implemented to the optimization of heliostat fields. Zhang et al. presented an efficient code combining Rosen projection method and simulated annealing smart algorithm to optimize the heliostat field layout [19]. Piroozmand et al. optimized a multi-tower heliostat field layout using particle swarm optimization (PSO) algorithm [3]. Of all the intelligence algorithms, genetic algorithm (GA) and PSO are the two most used algorithms, and have been successfully used to optimize a variety of engineering problems. However, both of the algorithms have merits and demerits. Therefore, when considering the advantages of both the algorithms, a hybrid algorithm named PSO-GA is proposed to optimize the heliostat field layouts in this study.

From the literatures available, it is clear that the aspects of heliostat research mainly focus on codes to calculate heliostat field efficiency, methods to calculate the efficiency more accurate and faster, and optimization of heliostat field layouts. However, in the aspect of heliostat field optimization, most of the studies optimize the heliostat field using the heliostat field efficiency as the objective function. However, a heliostat field with higher efficiency does not indicate that the field has better economic performances. In our previous study [20], a heliostat field was optimized using a PSO-GA method to determine the highest potential daily energy collection. In this paper, the heliostat field is optimized on annual basis and ECUC is optimized as the objective function. Therefore, the aim of this paper is to optimize the heliostat field to obtain the highest possible ECUC using the PSO-GA method. Servicing this aim, the contents of this paper are: (1) Mathematical models of a heliostat field and PSO-GA are coded in Matlab; (2) A heliostat field in Lhasa is optimized to determine the highest possible annual ECUC; (3) Annual performances of optimized and un-optimized heliostat field are analyzed and compared, and effects of some key parameters on the heliostat field are also investigated. 


\section{Mathematical Model}

Mathematical models of a circular heliostat field with a columnar receiver and a hybrid PSO-GA algorithm are coded in Matlab. The heliostat field model includes two main parts, a preliminary heliostat field generation and optical efficiency calculation. The basic parameters of a heliostat field are shown in Table 1 [12]. Based on our previous study [20], $\mathrm{Nhel}_{1}$ is set as 30.

Table 1. Main parameters of heliostat used.

\begin{tabular}{ccc}
\hline Parameter & Value & Unite \\
\hline Tower optical height & 140 & $\mathrm{~m}$ \\
Receiver radius & 4.0 & $\mathrm{~m}$ \\
Receiver height & 9.0 & $\mathrm{~m}$ \\
Heliostat total height & 9.752 & $\mathrm{~m}$ \\
Heliostat total width & 12.305 & $\mathrm{~m}$ \\
Heliostat pedestal height & 5 & $\mathrm{~m}$ \\
Standard deviation surface error & 0.94 & $\mathrm{mrad}$ \\
Standard deviation tracking error & 0.63 & $\mathrm{mrad}$ \\
Standard deviation of sunshape & 2.51 & $\mathrm{mrad}$ \\
Effective reflectivity & $0.88 \times 0.95$ & - \\
Number of zones in the field & 3 & - \\
Number of heliostats in first row & 30 & - \\
\hline
\end{tabular}

\subsection{A Preliminary Heliostat Field Generation}

In this part, a radial staggered layout heliostat field is used. In this configuration, the heliostats are placed in rings around the central tower and the heliostats stand in between two heliostats of the ring in front, which can considerably reduce the shadowing and blocking influence [21]. The variables that are used to define the heliostat field layout are presented in Figure 1.

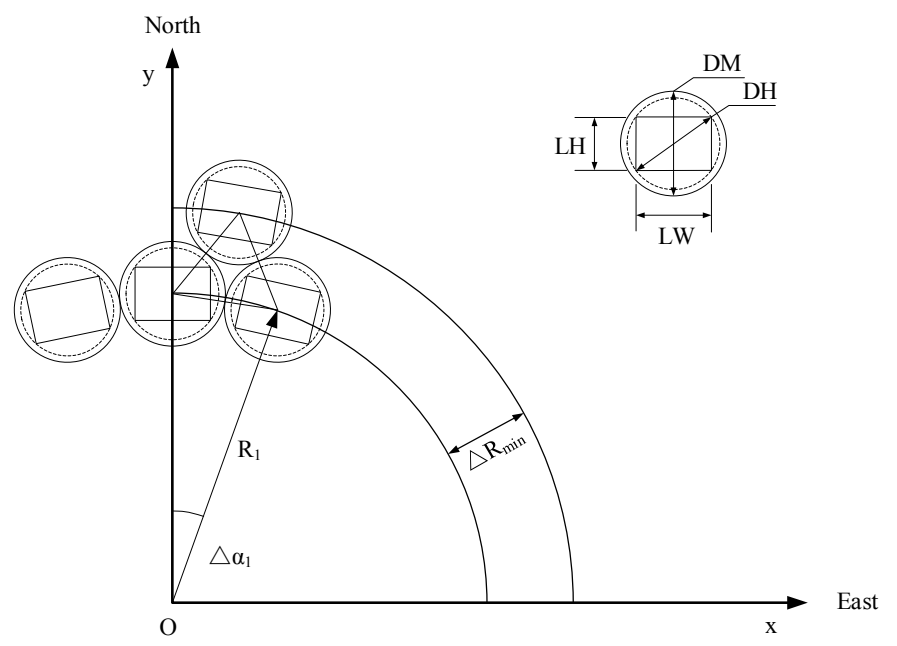

Figure 1. Fundamental definitions in the heliostat field.

In Figure 1, DM is the distance between the center of two adjacent heliostats, and can be calculated by Equation (1) [22]:

$$
\mathrm{DM}=\mathrm{DH}+\operatorname{desp}=\left[\sqrt{1+(\mathrm{LW} / \mathrm{LH})^{2}}+x\right] \cdot \mathrm{LH}
$$

$x$ is the optimization parameter, which can be used to control the azimuthal spacing between two adjoining heliostats. 
The minimum radial increment can be obtained by [22]:

$$
\Delta \mathrm{R}_{\min } \cong \mathrm{DM} \cdot \cos 30^{\circ}
$$

To optimize the radial distance in different zones, an optimization parameter $y_{i}$ is introduced into Equation (7). Thus, the modified equation of radial distance is as follows:

$$
\Delta \mathrm{R}_{i}=y_{i} \cdot \mathrm{DM} \cdot \cos 30^{\circ}(i=1,2,3)
$$

The azimuth angular spacing between contiguous heliostats in the first zone, which remains the same, is defined as [22].

$$
\Delta \alpha_{1}=2 \times \arcsin \left[\mathrm{DM} / 2 \mathrm{R}_{1}\right] \cong \mathrm{DM} / \mathrm{R}_{1}
$$

The length of the azimuth spacing will gradually increase as the radius of the row increase in radial stagger configuration $[11,21,23,24]$. A new zone would be formed when an additional heliostat can be placed between neighboring heliostats in the same row. Thus, the azimuth angular spacing of the second zone $\left(\Delta \alpha_{2}\right)$ and the third zone $\left(\Delta \alpha_{3}\right)$ should be:

$$
\begin{aligned}
& \Delta \alpha_{2}=\Delta \alpha_{1} / 2=\mathrm{DM} / \mathrm{R}_{2} \\
& \Delta \alpha_{3}=\Delta \alpha_{1} / 4=\mathrm{DM} / \mathrm{R}_{3}
\end{aligned}
$$

Moreover, the same radial distances in different zones, so the number of rows in different zones can be obtained by [22]:

$$
\begin{aligned}
& \text { Nrows }_{1}=\text { round }\left[\left(\mathrm{R}_{2}-\mathrm{R}_{1}\right) / \Delta \mathrm{R}_{1}\right] \\
& \text { Nrows }_{2}=\text { round }\left[\left(\mathrm{R}_{3}-\mathrm{R}_{2}\right) / \Delta \mathrm{R}_{2}\right] \\
& \text { Nrows }_{3}=\text { round }\left[\left(\mathrm{R}_{4}-\mathrm{R}_{3}\right) / \Delta \mathrm{R}_{3}\right]
\end{aligned}
$$

In Equations (7)-(9), round indicates that the quotient is rounded off to the next lower integer because Nrows $\mathrm{s}_{\mathrm{i}}$ is an integer. The number of heliostats in each row for the different zones can be obtained as follows [22]:

$$
\begin{gathered}
\text { Nhel }_{1}=2 \pi / \Delta \alpha_{1}=2 \pi \mathrm{R}_{1} / \mathrm{DM} \\
\text { Nhel }_{2}=4 \pi \mathrm{R}_{1} / \mathrm{DM} \\
\text { Nhel }_{3}=8 \pi \mathrm{R}_{1} / \mathrm{DM}
\end{gathered}
$$

Therefore, the number of heliostats of the heliostat field can be calculated by:

$$
\text { Num }=\sum \text { Nrows }_{i} \cdot \text { Nhel }_{i}(i=1,2,3)
$$

The land area of the heliostat field can be obtained by [25]:

$$
\text { Area }=\pi\left(R_{\text {last }}+0.5 \mathrm{DM}\right)^{2}
$$

\subsection{Optical Efficiency Calculation}

Based on Sandia nomenclature, instantaneous optical efficiency of a heliostat is defined by [26]:

$$
\eta(x, y, t)=\rho \cdot \cos (x, y, t) f_{a t}(x, y) f_{s b}(x, y, t) f_{\text {int }}(x, y, t)
$$

The cosine factor is the most influential optical factor on heliostats' performance, which is the incidence cosine between the incident ray and the normal to the heliostat surface and can be calculated by the incident vector and the reflect vector. 
The incident vector, which is pointing to the sun, can be gained by:

$$
\overrightarrow{\mathrm{S}}=(-\cos \alpha \sin \beta,-\cos \alpha \cos \beta, \sin \alpha)
$$

$\alpha$ and $\beta$ can be obtained as follows [27]:

$$
\begin{gathered}
\alpha=\arcsin (\cos \phi \cos \delta \cos \omega+\sin \phi \sin \delta) \\
\beta=\operatorname{sgn}(\omega)|\arccos ((\sin \alpha \sin \phi-\sin \delta) /(\cos \alpha \cos \phi))| \\
\omega=15 \pi(t-12) / 180 \\
\delta=\frac{23.45 \pi}{180} \sin \left(2 \pi \frac{284+\mathrm{n}}{365}\right)
\end{gathered}
$$

The reflect vector, which is pointing to the receiver, can be obtained by the coordinates of the center of the heliostats and the receiver. Thus, cosine factor can be gained by:

$$
\cos =\cos (\arccos (\vec{S} \cdot \vec{R}) / 2)
$$

The atmospheric attenuation factor is another important factor, which calculates the beam losses of the reflected ray. Atmospheric attenuation factor depends on the distance between the heliostat and the receiver which can be obtained by [12]:

$$
\mathrm{f}_{\mathrm{at}}=\left\{\begin{array}{c}
0.99321-0.0001176 \mathrm{~d}_{\mathrm{hr}}+1.97 \times 10^{-8} \mathrm{~d}_{\mathrm{hr}}^{2} \mathrm{~d}_{\mathrm{hr}} \leq 1000 \mathrm{~m} \\
\exp \left(-0.0001106 \mathrm{~d}_{\mathrm{hr}}\right) \mathrm{d}_{\mathrm{hr}}>1000 \mathrm{~m}
\end{array}\right.
$$

The intercept factor is caused by tracking error, shape of sun, mirror aberrations, and mirror surface non-uniformity. In this study, the intercept factor is calculated by the HFLCAL model, which is a simpler and more accurate method when compared to the UNIZAR model [7]. This model considers that all of the heliostats are well-canted concentrating facets of spherical curvatures. The intercept factor can be calculated by:

$$
\mathrm{f}_{\text {int }}=\frac{1}{2 \pi \sigma_{\text {tot }}^{2}} \int_{\mathrm{x}^{\prime}} \int_{\mathrm{y}^{\prime}} \exp \left(-\frac{\mathrm{x}^{\prime 2}+\mathrm{y}^{\prime 2}}{2 \sigma_{\text {tot }}^{2}}\right) d \mathrm{y}^{\prime} \mathrm{dx}
$$

The shadowing loss happens when the incoming rays are obstructed by adjacent heliostats before they hit the problem heliostat. The blocking loss occurs when the reflected rays from the problem heliostat are blocked by adjacent heliostats before they reach the receiver. The shadowing and blocking factor is classified by the fraction of the heliostat area that is free of shadowing and blocking. Shadowing and blocking factor is related to the sun position during the day and the locations of the target heliostat and adjacent heliostats. Thus, the shadowing and blocking factor is the most complex and difficult factor to be calculated. In this study, the method that is used to calculate the shadowing and blocking factor is introduced in Refs. [22,28,29], which can not only save the calculation time but also ensure the accuracy of the calculation results. In this method, the projection shape of shadowing or blocking heliostat on the problem heliostat is assumed to be identical and parallel to the surface of the problem heliostat. Because of the radial staggered configuration, for blocking, only three heliostats are checked. As for shadowing, three other shadowing heliostats and former three blocking heliostats are checked.

The optical efficiency model has been validated in our previous work [20], and the results showed that our model developed in Matlab can be trusted for further analysis. 


\subsection{Annual Averaged Efficiency and Annual Energy Collected Per Unit Cost}

In a real STPP, the heliostat field starts to work, when the solar altitude angle is higher than $15^{\circ}$ and the DNI is higher than $150 \mathrm{~W} / \mathrm{m}^{2}$ [30]. Therefore, the annual averaged efficiency of the heliostat field can be obtained by:

$$
\eta_{\text {annual }}=\frac{\sum_{\mathrm{j}=1}^{365} \sum_{\mathrm{i}=1}^{\mathrm{Num}} \eta_{\text {hel,daily }}}{365 \times \text { Num }}
$$

In Equation (16), the daily averaged efficiency of a heliostat ( $\eta_{\text {hel,daily }}$ ) can be obtained by:

$$
\eta_{\text {hel,daily }}=\frac{\int_{\mathrm{t} \mid \mathrm{DNI} \geq 150, \alpha \geq 15^{\circ}} \eta \mathrm{dt}}{\int_{\mathrm{t} \mid \mathrm{DNI} \geq 150, \alpha \geq 15^{\circ}} \mathrm{dt}}
$$

Then, the daily energy collected can be obtained.

$$
\mathrm{E}=0.0036 \mathrm{~A}_{\mathrm{h}} \sum_{\mathrm{i}=1}^{\mathrm{Num}} \sum_{\mathrm{DNI}_{\mathrm{i}} \geq 150, \alpha_{\mathrm{i}} \geq 15^{\circ}} \eta \mathrm{DNI} \mathrm{i}_{\mathrm{i}}
$$

The annual energy collected can be calculated by:

$$
\mathrm{E}_{\text {annual }}=\sum_{\mathrm{i}=1}^{365} \mathrm{E}_{\mathrm{i}}
$$

The investment of the heliostat filed can be calculated by [31,32]:

$$
\begin{gathered}
\mathrm{I}_{\text {field }}=\mathrm{I}_{\mathrm{col}}+\mathrm{I}_{\text {tower }}+\mathrm{I}_{\text {receiver }}+\mathrm{I}_{\text {land }} \\
\mathrm{I}_{\mathrm{col}}=\mathrm{c}_{\mathrm{col}} \mathrm{A}_{\mathrm{h}} \text { Num } \\
\mathrm{I}_{\text {tower }}=3 \times 10^{6} \times \exp \left[0.0133\left(\frac{\mathrm{H}_{\text {tow }}-\mathrm{RH}}{2}+\frac{\mathrm{H}_{\mathrm{col}}}{2}\right)\right] \\
\mathrm{I}_{\text {receiver }}=55402800\left(\frac{2 \pi \cdot \mathrm{RH} \cdot \mathrm{RW}}{1110}\right)^{0.7} \\
\mathrm{I}_{\text {land }}=\mathrm{c}_{\text {land }}\left(1.5 \text { Area }+1.8 \times 10^{5}\right)
\end{gathered}
$$

$\mathrm{c}_{\mathrm{col}}$ and $\mathrm{c}_{\mathrm{land}}$ are set to $126 \mathrm{USD} / \mathrm{m}^{2}$ and $0.62 \mathrm{USD} / \mathrm{m}^{2}$ [31].

Therefore, the annual ECUC can be obtained:

$$
\mathrm{ECUC}=\frac{\mathrm{E}_{\text {annual }}}{\mathrm{I}_{\text {field }}}
$$

\subsection{Hybrid PSO-GA Algorithm}

GA and PSO, two intelligent optimization algorithms, have been successfully applied in many optimization problems. GA is a computational model that is inspired by the natural selection and genetic mechanism of Darwin's biological evolution theory. In GA, selection, crossover, and mutation are three of the most used genetic operations. Selection is a process where several individuals with higher fitness are selected from the whole population to breed a new generation. After selection, crossover, and mutation are applied to generate a new population from those selected individuals. Crossover is a process that two chosen parent individuals swap part of their genes to generate new individuals. Mutation alters one or more gene values in an individual, which can maintain genetic diversity from one generation to the next and the GA population can come to a better solution through mutation operation. PSO is originally inspired by the behavior of the birds' cluster. As an optimization method, PSO is a population-based algorithm in which each particle updates its position and velocity 
vectors in each iteration by tracking its own previous best position (pbest) and group previous best position (gbest). In each iteration, each particle updates its velocity and position vectors according to the Equations (34)-(36).

$$
\begin{gathered}
\mathrm{v}_{\mathrm{i}}(\mathrm{t}+1)=\mathrm{m} \cdot \mathrm{v}_{\mathrm{i}}(\mathrm{t})+\mathrm{c}_{1} \mathrm{r}_{1}\left(\text { pbest }_{\mathrm{i}}(\mathrm{t})-\mathrm{x}_{\mathrm{i}}(\mathrm{t})\right)+\mathrm{c}_{2} \mathrm{r}_{2}\left(\text { gbest }_{\mathrm{i}}(\mathrm{t})-\mathrm{x}_{\mathrm{i}}(\mathrm{t})\right) \\
\mathrm{x}_{\mathrm{i}}(\mathrm{t}+1)=\mathrm{x}_{\mathrm{i}}(\mathrm{t})+\mathrm{v}_{\mathrm{i}}(\mathrm{t}+1) \\
\mathrm{m}=\left\{\begin{array}{c}
\mathrm{m}_{\min }+\frac{\left(\mathrm{m}_{\max }-\mathrm{m}_{\min }\right)\left(\mathrm{fit}_{\mathrm{it}}-\mathrm{fit}_{\min }\right)}{\text { fit }_{\text {ave }}-\text { fit }_{\text {min }}} \\
\mathrm{m}_{\text {max }} \text { fit }>\mathrm{t}_{\text {ave }}
\end{array}\right.
\end{gathered}
$$

Each optimization algorithm has specific advantages and disadvantages. The idea of the hybrid algorithm can combine the merits of different optimization algorithm, but avoids their shortcomings [33]. Thus, hybrid optimization algorithms normally have a better optimization ability than one kind optimization algorithm alone. Similar to GA and PSO, the proposed PSO-GA is also a population-based optimization method. In this method, seven parameters $\mathrm{m}, \mathrm{c}_{1}, \mathrm{c}_{2}, \mathrm{r}_{1}, \mathrm{r}_{2}, \mathrm{P}_{\mathrm{c}}$, and $\mathrm{P}_{\mathrm{m}}$ are used to control the optimization process. $\mathrm{m}$ is the self-adaptive weight, which is used to control the algorithm capability of exploration based on the fitness of each particle in the previous generation population. In this study, $\mathrm{m}$ changes from 0.4 to $0.9 . \mathrm{c}_{1}$ and $\mathrm{c}_{2}$ are two acceleration coefficients, which are both set to 1.5. $r_{1}$ and $r_{2}$ are two random numbers distributed uniformly in the interval $[0,1]$. $P_{c}$ is the probability of crossover operation in the GA part of PSO-GA, which is set to $0.8 . P_{m}$ is the probability of GA's mutation operation in the GA part of PSO-GA, which is set to 0.3. In PSO-GA algorithm, first, a PSO population is randomly generated and pbest and gbest are determined according to the fitness of each particle. Next, the population is updated based on each particle's position and velocity vectors. Then, crossover and mutation operations are implemented to update the particles in the population further. Then, fitness is recalculated, and pbest and gbest are updated. Finally, check the stop criteria, which is when the current generation reaches the maximum generation (MG) or the fitness of the population keeps constant for 50 iterations. The flow chart of the hybrid PSO-GA is shown in Figure 2.

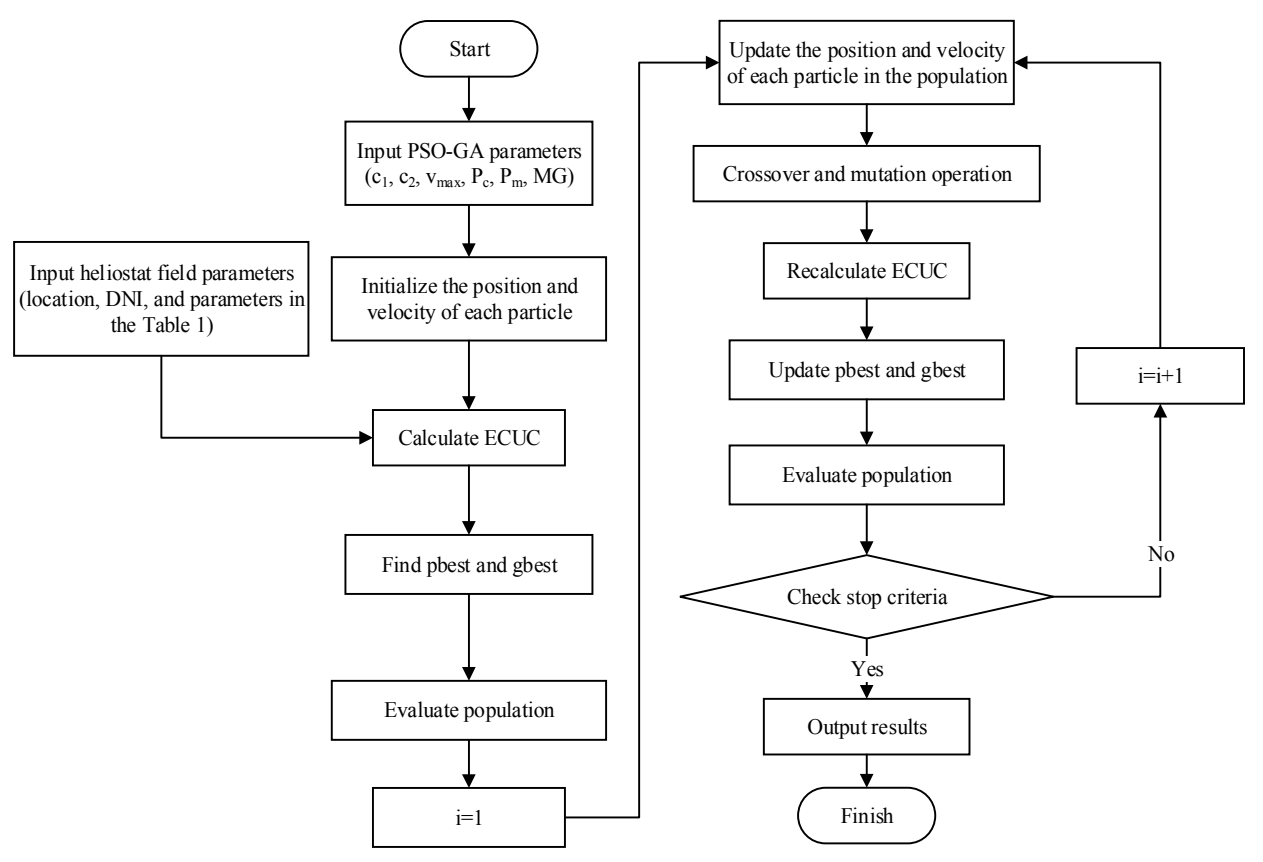

Figure 2. Flow chart of the hybrid particle swarm optimization (PSO)-genetic algorithm (GA). 


\section{Results and Discussion}

In this study, in order to obtain the highest potential annual ECUC, the heliostat field located in Lhasa $\left(29.67^{\circ} \mathrm{N}, 91.13^{\circ} \mathrm{E}\right)$ is optimized by the PSO-GA method. The yearly DNI distribution of Lhasa is derived from System Advisor Model (SAM) and is presented in Figure 3. In order to save optimization time, 12 special days in one year are used in the optimization process, which are recommended in Ref. [34] and listed in Table 2. The number of generations taken to reach the optimum result are listed in Table 3.

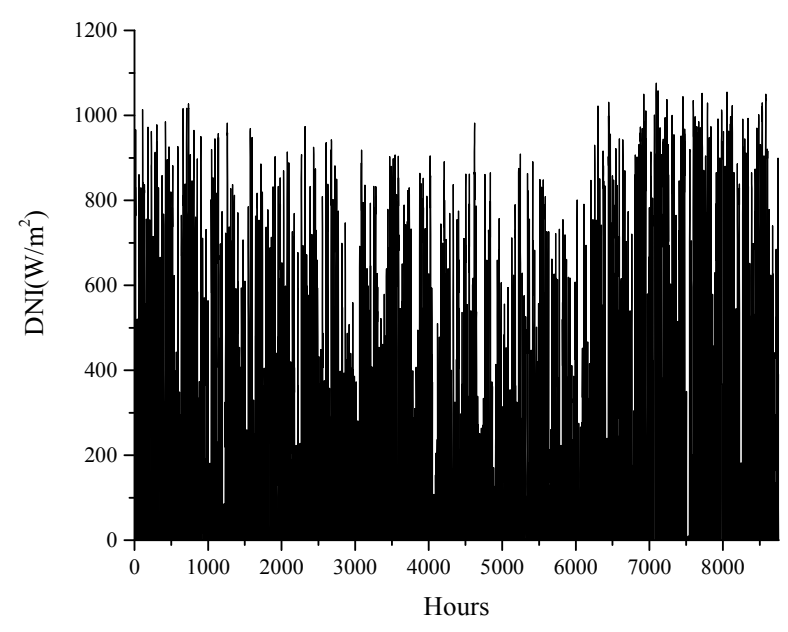

Figure 3. Yearly Direct Normal Irradiance (DNI) distribution of Lhasa.

Table 2. Recommended average days of month.

\begin{tabular}{ccc}
\hline Month & Average Day of Month (Date) & Day of the Year \\
\hline January & 17 & 17 \\
February & 16 & 47 \\
March & 16 & 75 \\
April & 15 & 105 \\
May & 15 & 135 \\
June & 11 & 162 \\
July & 17 & 198 \\
August & 16 & 228 \\
September & 15 & 258 \\
October & 15 & 288 \\
November & 14 & 318 \\
December & 10 & 344 \\
\hline
\end{tabular}

Table 3. Number of generations taken to reach the optimum result.

\begin{tabular}{ccc}
\hline Parameters & & Number of Generations \\
\hline Nhel $_{1}$ change & 25 & 127 \\
& 28 & 82 \\
& 30 & 120 \\
& 32 & 111 \\
Tower height change & 34 & 70 \\
$(\mathrm{~m})$ & 130 & 124 \\
& 135 & 121 \\
& 145 & 75 \\
Heliostat mirror cost change & 150 & 129 \\
$\left(\mathrm{USD} / \mathrm{m}^{2}\right)$ & 75 & 85 \\
& 100 & 125 \\
& 150 & 147 \\
& 175 & 145 \\
\hline
\end{tabular}




\subsection{Optimized Results}

Table 4 shows the optimized results of the heliostat field on annual basis. When compared with the un-optimized results, as can be seen from the table, the optimization parameters of radial distances in zones 1 and 2 are still equal to 1 . While the optimization parameters of radial distance in zone 3 and the additional safety distance are bigger than those of the un-optimized results. The optimization parameters of radial distance in zone 3 and additional safety distance are 1.2971 and 0.0785 , respectively. Therefore, the change of the optimization parameters of radial distance in zone 3 and the additional safety distance lead to the number of the heliostats decreasing from 3450 to 2850, but the heliostat field area increases from $1.10 \times 10^{6} \mathrm{~m}^{2}$ to $1.20 \times 10^{6} \mathrm{~m}^{2}$. After optimization, although the optimization parameters of radial distances in zones 1 and 2 are still equal to 1 , the heliostat field efficiencies of zones 1 and 2 slightly increase from 0.6907 to 0.6924 and from 0.6281 to 6311 , respectively. This is caused by the increase of the optimization parameter of the additional separation distance, which also influences $\Delta R_{1}$ and $\Delta R_{2}$. What is more, the change of the optimization parameters of radial distance in zone 3 and additional safety distance causes the heliostat field efficiency in zone 3 increase from 0.4669 to 0.5339 , nearly seven percentage points. As stated above, the efficiency of the heliostat field increases about six percentage points, which is mainly influenced by the increase of the heliostat field efficiency in zone 3. The increase of heliostat field efficiency and the decrease of heliostat number cause that $\mathrm{E}_{\text {annual }}$ decreases from $9.87 \times 10^{5} \mathrm{GJ}$ to $9.08 \times 10^{5} \mathrm{GJ}$ and ECUC increases from $12.50 \mathrm{MJ} / \mathrm{USD}$ to $12.97 \mathrm{MJ} / \mathrm{USD}$, about $3.8 \%$ improvement. Figure 4 shows the change of the un-optimized and optimized heliostat field efficiencies per hour in a year. From the figure, the optimized efficiency is higher than the un-optimized efficiency. This is because, after optimization, the radial and angular distances between neighboring heliostats are bigger than these of un-optimized field, which cause the great improvement in shadowing and blocking factor. What is more, the variation tendencies of un-optimized and optimized heliostat field efficiencies are similar, which increase at first and then decrease.

Table 4. Optimization results of the heliostat field on annual basis using PSO-GA algorithm.

\begin{tabular}{ccc}
\hline & Un-Optimized Field & Optimized Field \\
\hline $\mathrm{y}_{1}$ & 1.0000 & 1.0000 \\
$\mathrm{y}_{2}$ & 1.0000 & 1.0000 \\
$\mathrm{y}_{3}$ & 1.0000 & 1.2971 \\
$\mathrm{x}$ & 0.0000 & 0.0785 \\
$\mathrm{Num}$ & 3450 & 2850 \\
Area $\left(\times 10^{6} \mathrm{~m}^{2}\right)$ & 1.10 & 1.20 \\
$\eta_{\text {annual }}$ & 0.5074 & 0.5648 \\
$\eta_{\text {zone1 }}$ & 0.6907 & 0.6924 \\
$\eta_{\text {zone2 }}$ & 0.6281 & 0.6311 \\
$\eta_{\text {zone3 }}$ & 0.4669 & 0.5339 \\
$\mathrm{E}_{\text {annual }}\left(\times 10^{5} \mathrm{GJ}\right)$ & 9.87 & 9.08 \\
$\mathrm{ECUC}(\mathrm{MJ} / \mathrm{USD})$ & 12.50 & 12.97 \\
\hline
\end{tabular}

The contours of the annual averaged efficiency of the heliostat field are shown in Figure 5. From the figure, the annual averaged efficiencies of north heliostat field are higher than these of the south heliostat field. After optimization, the radius of heliostat field increase from $583 \mathrm{~m}$ to $629 \mathrm{~m}$, and the efficiency of the heliostat field is higher than that of the un-optimized field. 


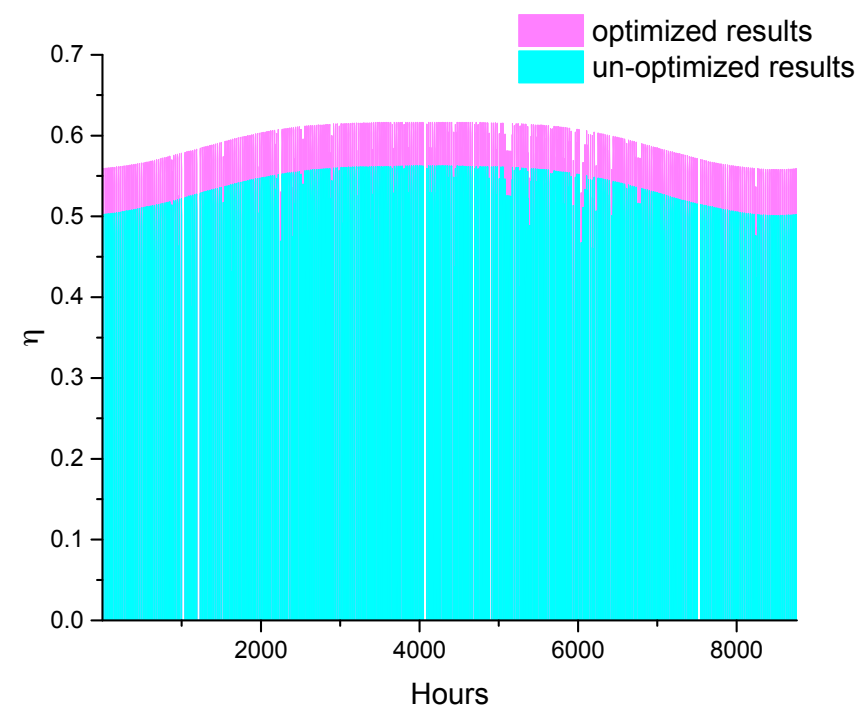

Figure 4. The heliostat field efficiency of the whole year.

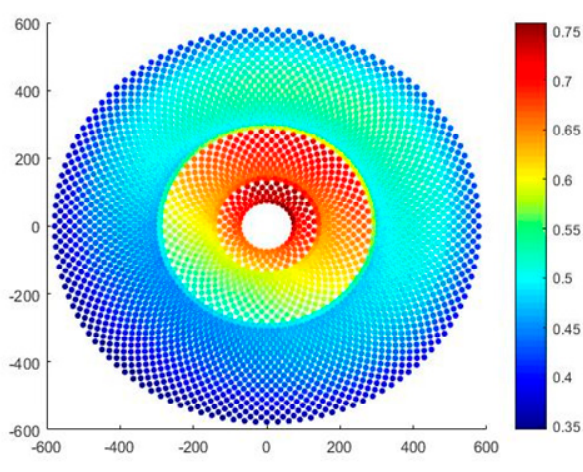

(a)

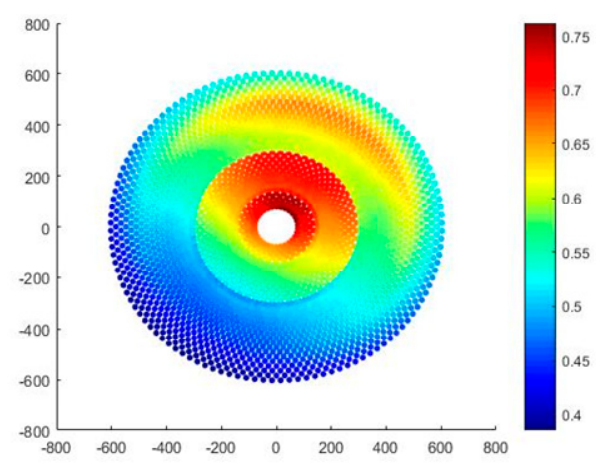

(b)

Figure 5. The contours of the annual averaged efficiency of heliostat field: (a) un-optimized result and (b) optimized result.

\subsection{Sensitivity Analysis}

In this study, the effects of $\mathrm{Nhel}_{1}$, tower height, and heliostat mirror collector cost have been explored.

\subsubsection{Effect of $\mathrm{Nhel}_{1}$}

The number of Nhel $_{1}$ has an important influence on the heliostat field layout and the heliostat field optical efficiency. Therefore, the effects of $\mathrm{Nhel}_{1}$ on the heliostat field performances have been investigated, when the Nhel ${ }_{1}$ changes between 25 and 34, and the results are shown in Figure 6. As can be seen from Figure 6, the ECUC of the un-optimized heliostat field increase at first and then show a downward trend. When $\mathrm{Nhel}_{1}$ is 30 , ECUC reaches the maximum value, about $12.45 \mathrm{MJ} / \mathrm{USD}$. However, for the optimized heliostat field, ECUC shows an upward trend with the increase of Nhel ${ }_{1}$. When the $\mathrm{Nhel}_{1}$ increases from 25 to 34, ECUC grows up from 12.22 MJ/USD to 13.29 MJ/USD. What is more, the gap between un-optimized field and optimized field shows an upward trend with the increase of $\mathrm{Nhel}_{1}$ as well. The $\mathrm{E}_{\text {annual }}$ of optimized field is higher than the $\mathrm{E}_{\text {annual }}$ of un-optimized field when $\mathrm{Nhel}_{1}$ is 25 . This is because the Num does not change after optimization, but the efficiency of the optimized field is higher that of the un-optimized field. While the values of $E_{\text {annual }}$ of optimized 
field are higher than these of un-optimized field when $\mathrm{Nhel}_{1}$ changes from 28 to 34 . This is caused by the change of Num and efficiency of the field.

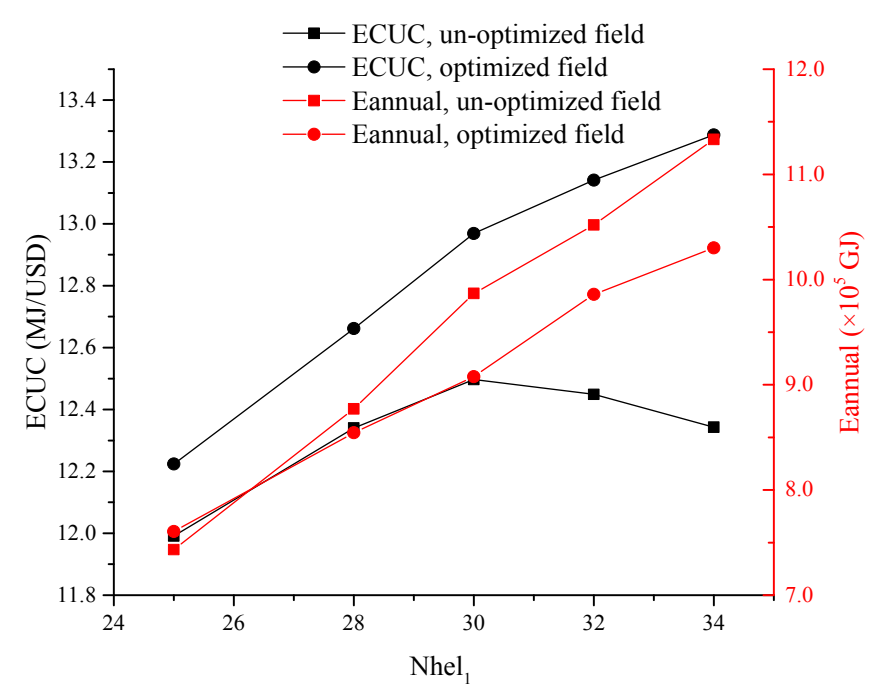

Figure 6. Effect of $\mathrm{Nhel}_{1}$ on the energy collected of unit cost and annual energy collected.

\subsubsection{Effect of Tower Height}

Tower height has an important influence on the heliostat field layout and heliostat field optical efficiency as well. Therefore, the effects of tower height on heliostat field performances have been investigated, when the tower height changes between $130 \mathrm{~m}$ and $150 \mathrm{~m}$, and the results are demonstrated in Figure 7. As can be seen from Figure 7, for both the un-optimized and optimized heliostat fields, ECUCs show an upward trend with the tower height. Nevertheless, the increase rate of the optimized field is lower than that of the un-optimized field. Therefore, the gap between the un-optimized field and optimized field gradually declines with the increase of tower height. For $\mathrm{E}_{\text {annual }}$, the values of un-optimized and optimized heliostat field show an upward trend with tower height as well.

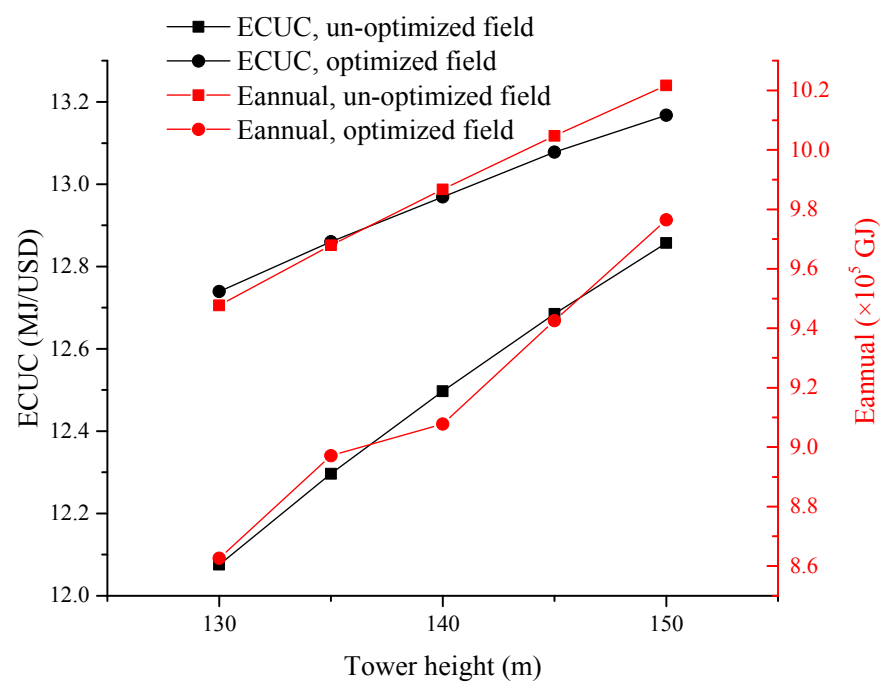

Figure 7. Effect of tower height on the energy collected of unit cost and annual energy collected. 


\subsubsection{Effect of Heliostat Mirror Collector Cost}

The cost of the heliostat mirror collector is an important factor in the heliostat field cost, which accounts for over $70 \%$ of the cost. Changing the cost of the heliostat mirror collector has an important influence on the performances of the heliostat field. In Ref. [35], it pointed out that the cost of the heliostat mirror is between $150 \mathrm{USD} / \mathrm{m}^{2}$ to $200 \mathrm{USD} / \mathrm{m}^{2}$ in 2013 , and the cost will gradually decline and may reach $75 \mathrm{USD} / \mathrm{m}^{2}$ in the future. Thus, the effects of the cost of heliostat mirror collector on the heliostat field when the cost varies from $75 \mathrm{USD} / \mathrm{m}^{2}$ to $175 \mathrm{USD} / \mathrm{m}^{2}$ are discussed. The results are shown in Figure 8. As can be seen from Figure 8, for both the un-optimized and optimized heliostat fields, ECUCs show a downward trend with an increase of heliostat mirror collector cost. What is more, the gap between un-optimized heliostat field and optimized heliostat field gradually increases with the increase of heliostat mirror collector cost. The $E_{\text {annual }}$ of un-optimized field does not change with the heliostat mirror collector cost. While the $\mathrm{E}_{\text {annual }}$ of optimized field decreases with the heliostat mirror collector cost, which is mainly caused by the Num in the heliostat field.

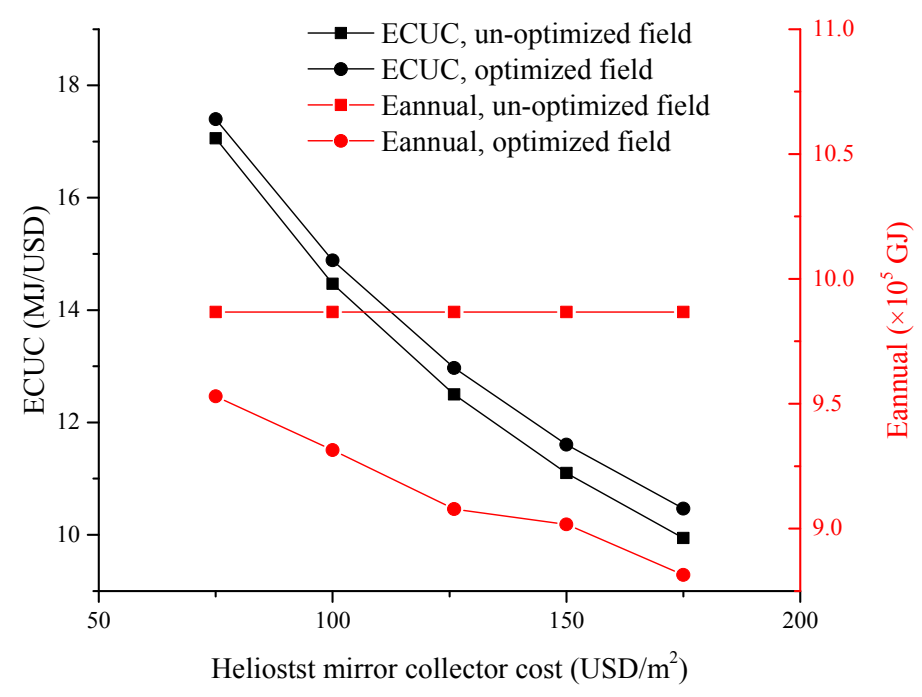

Figure 8. Effect of heliostat mirror collector cost on energy collected of unit cost and annual energy collected.

\section{Conclusions}

In this study, in order to optimize the heliostat field to obtain the highest annual ECUC, mathematical models of a heliostat field and PSO-GA are developed in Matlab and a heliostat field in Lhasa is analyzed as an example. Then, the effects of some key parameters on ECUC are also explored. When compared with the un-optimized results, the optimization parameters of radial distances in zones 1 and 2 are still equal to 1 . While the optimization parameters of radial distance in zone 3 and additional safety distance are 1.2971 and 0.0785 , respectively. After optimization, the annual efficiency of the heliostat field increases from 0.5074 to 0.5648 , increased about $5.7 \%$. What is more, the ECUC increases from 12.50 MJ/USD to $12.97 \mathrm{MJ} / \mathrm{USD}$, increased about 3.8\%. Studies on the key parameters show that: for un-optimized filed, ECUC first peaks and then declines with the increase of $\mathrm{Nhel}_{1}$. When the Nhel ${ }_{1}$ is 30 , the heliostat field has the biggest ECUC. To the contrary, for optimized field, ECUC increases with Nhel ${ }_{1}$. What is more, for both un-optimized and optimized fields, ECUCs increase with tower height and decrease with the cost of heliostat mirror collector.

Acknowledgments: The research work is supported by National Major Fundamental Research Program of China (No. 2015CB251505), China National Natural Science Foundation (No. 51776063), Fundamental Research Funds for the Central Universities (2016XS29, 2016YQ04). 
Author Contributions: All authors contributed to the paper. Chao Li and Rongrong Zhai carried out the simulations and performance analysis, and wrote the paper. Yongping Yang supervised the research and finalized the paper.

Conflicts of Interest: The authors declare no conflict of interest.

\section{Nomenclature}

\begin{tabular}{|c|c|}
\hline$A_{h}$ & area of a heliostat, $\mathrm{m}^{2}$ \\
\hline Area & land area of the heliostat field, $\mathrm{m}^{2}$ \\
\hline$c_{1}$ and $c_{2}$ & acceleration coefficient \\
\hline$c_{\mathrm{col}}$ & unit cost of heliostat mirror collector, USD $/ \mathrm{m}^{2}$ \\
\hline$c_{\text {land }}$ & unit cost of land purchase, USD $/ \mathrm{m}^{2}$ \\
\hline $\cos$ & cosine factor \\
\hline $\mathrm{DH}$ & diagonal of heliostat, $\mathrm{m}$ \\
\hline $\mathrm{DM}$ & distance between the center of two contiguous heliostats, $\mathrm{m}$ \\
\hline DNI & Direct Normal Irradiance, $\mathrm{W} / \mathrm{m}^{2}$ \\
\hline $\mathrm{D}$ & general dimension of the heliostat, $\mathrm{m}$ \\
\hline desp & additional separation distance, $\mathrm{m}$ \\
\hline$d_{h r}$ & distance between the heliostat and the receiver, $\mathrm{m}$ \\
\hline $\mathrm{E}$ & daily energy collected, MJ \\
\hline $\mathrm{E}_{\text {annual }}$ & annual energy collected, GJ \\
\hline ECUC & energy collected of unit cost, MJ/USD \\
\hline $\mathrm{f}_{\text {at }}$ & atmospheric attenuation factor \\
\hline$f_{\text {int }}$ & intercept factor \\
\hline$f_{s b}$ & shadowing and blocking factor \\
\hline fit & fitness of the calculated particle \\
\hline GA & genetic algorithm \\
\hline gbest & best solution found by the whole swarm \\
\hline $\mathrm{H}_{\mathrm{col}}$ & heliostat pedestal height, $\mathrm{m}$ \\
\hline $\mathrm{H}_{\text {tow }}$ & tower height, $\mathrm{m}$ \\
\hline $\mathrm{I}_{\mathrm{col}}$ & investment of heliostat mirror collector, USD \\
\hline $\mathrm{I}_{\text {field }}$ & investment of the heliostat field, USD \\
\hline $\mathrm{I}_{\text {land }}$ & investment of land purchase, USD \\
\hline $\mathrm{I}_{\text {receiver }}$ & investment of the receiver, USD \\
\hline $\mathrm{I}_{\text {tower }}$ & investment of the central tower, USD \\
\hline $\mathrm{LH}$ & height of the heliostat, $\mathrm{m}$ \\
\hline LW & width of the heliostat, $\mathrm{m}$ \\
\hline MG & maximum generation \\
\hline $\mathrm{m}$ & self-adaptive weight \\
\hline Nhel $_{i}$ & number of heliostats in each row in the $i$ th zone \\
\hline Nrows $_{i}$ & number of rows in the $i$ th zone \\
\hline Num & number of heliostats of the heliostat field \\
\hline $\mathrm{n}$ & number of the calculating day in the year \\
\hline pbest & best solution found by particle itself \\
\hline PSO & particle swarm optimization algorithm \\
\hline $\mathrm{R}$ & reflect vector \\
\hline $\mathrm{R}_{i}$ & radius of the first row in the $i$ th zone, $\mathrm{m}$ \\
\hline $\mathrm{R}_{\text {last }}$ & radius of the last row in the third zone \\
\hline RH & receiver height, $\mathrm{m}$ \\
\hline RW & receiver radius, $\mathrm{m}$ \\
\hline $\mathrm{r}_{1}$ and $\mathrm{r}_{2}$ & random number \\
\hline S & incident vector \\
\hline SPTT & solar tower power plant \\
\hline t & solar time \\
\hline
\end{tabular}




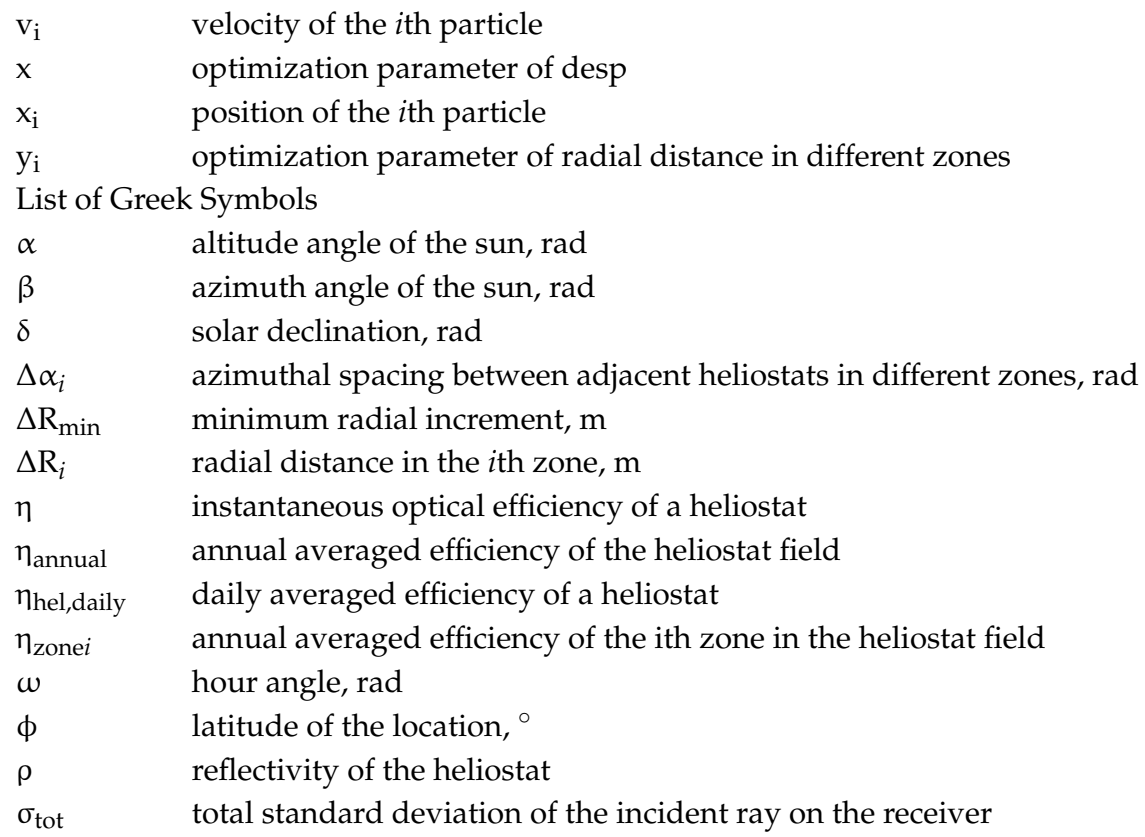

\section{References}

1. Ye, B.; Zhang, K.; Jiang, J.; Miao, L.; Li, J. Towards a 90\% renewable energy future: A case study of an island in the South China Sea. Energy Convers. Manag. 2017, 142, 28-41. [CrossRef]

2. Ye, B.; Yang, P.; Jiang, J.; Miao, L.; Shen, B.; Li, J. Feasibility and economic analysis of a renewable energy powered special town in China. Resour. Conserv. Recycl. 2017, 121, 40-50.

3. Piroozmand, P.; Boroushaki, M. A computational method for optimal design of the multi-tower heliostat field considering heliostats interactions. Energy 2016, 106, 240-252.

4. Emes, M.J.; Arjomandi, M.; Nathan, G.J. Effect of heliostat design wind speed on the levelised cost of electricity from concentrating solar thermal power tower plants. Sol. Energy 2015, 115, 441-451. [CrossRef]

5. Zeyghami, M.; Khalili, F. Performance improvement of dry cooled advanced concentrating solar power plants using daytime radiative cooling. Energy Convers. Manag. 2015, 106, 10-20. [CrossRef]

6. Reyes-Belmonte, M.A.; Sebastián, A.; Romero, M.; González-Aguilar, J. Optimization of a recompression supercritical carbon dioxide cycle for an innovative central receiver solar power plant. Energy 2016, 112, 17-27.

7. Besarati, S.M.; Yogi Goswami, D. A computationally efficient method for the design of the heliostat field for solar power tower plant. Renew. Energy 2014, 69, 226-232. [CrossRef]

8. Wei, X.; Lu, Z.; Wang, Z.; Yu, W.; Zhang, H.; Yao, Z. A new method for the design of the heliostat field layout for solar tower power plant. Renew. Energy 2010, 35, 1970-1975. [CrossRef]

9. Schwarzbözl, P.; Schmitz, M.; Pitz-Paal, R. Visual HFLCAL—A Software Tool for Layout and Optimisation of Heliostat Fields. In Proceedings of the Solarpaces 2009, Berlin, Germany, 15-18 Septmeber 2009.

10. Leary, P.L.; Hankins, J.D. User's Guide for MIRVAL: A Computer Code for Comparing Designs of Heliostat-Receiver Optics for Central Receiver Solar Power Plants; Central Receivers; Sandia National Laboratories (SNL-CA): Livermore, CA, USA, 1979.

11. Kistler, B.L. A user's manual for DELSOL3: A computer code for calculating the optical performance and optimal system design for solar thermal central receiver plants. In Proceedings of the 3rd Central-European Workshop on Services and their Composition (ZEUS), Karlsruhe, Germany, 21-22 February 2011; pp. 24-25.

12. Collado, F.J.; Guallar, J. A review of optimized design layouts for solar power tower plants with campo code. Renew. Sustain. Energy Rev. 2013, 20, 142-154. [CrossRef]

13. Cádiz, P.; Frasquet, M.; Silva, M.; Martínez, F.; Carballo, J. Shadowing and blocking effect optimization for a variable geometry heliostat field. Energy Procedia 2015, 69, 60-69.

14. Wei, X.; Lu, Z.; Yu, W.; Wang, Z. A new code for the design and analysis of the heliostat field layout for power tower system. Sol. Energy 2010, 84, 685-690. [CrossRef] 
15. Kim, S.; Lee, I.; Lee, B.J. Development of performance analysis model for central receiver system and its application to pattern-free heliostat layout optimization. Sol. Energy 2017, 153, 499-507. [CrossRef]

16. Noone, C.J.; Torrilhon, M.; Mitsos, A. Heliostat field optimization: A new computationally efficient model and biomimetic layout. Sol. Energy 2012, 86, 792-803. [CrossRef]

17. Gadalla, M.; Saghafifar, M. Thermo-economic and comparative analyses of two recently proposed optimization approaches for circular heliostat fields: Campo radial-staggered and biomimetic spiral. Sol. Energy 2016, 136, 197-209. [CrossRef]

18. Eddhibi, F.; Ben Amara, M.; Balghouthi, M.; Guizani, A. Design and analysis of a heliostat field layout with reduced shading effect in southern Tunisia. Int. J. Hydrogen Energy 2017, 42, 28973-28996. [CrossRef]

19. Zhang, M.; Yang, L.; Xu, C.; Du, X. An efficient code to optimize the heliostat field and comparisons between the biomimetic spiral and staggered layout. Renew. Energy 2016, 87, 720-730. [CrossRef]

20. Li, C.; Zhai, R.; Liu, H.; Yang, Y.; Wu, H. Optimization of a heliostat field layout using hybrid PSO-GA algorithm. Appl. Therm. Eng. 2018, 128, 33-41. [CrossRef]

21. Lipps, F.W. Theory of Cellwise Optimization for Solar Central Receiver System; No. SAND-85-8177; Houston University: Houston, TX, USA, 1985.

22. Collado, F.J.; Guallar, J. Campo: Generation of regular heliostat fields. Renew. Energy 2012, 46, 49-59. [CrossRef]

23. Lipps, F.W.; Vant-Hull, L.L. A cellwise method for the optimization of large central receiver systems. Sol. Energy 1978, 20, 505-516. [CrossRef]

24. Lipps, F.W.; Vanthull, L.L. Shading and blocking geometry for a solar tower concentrator with rectangular mirrors. In Proceedings of the American Society of Mechanical Engineers, Winter Meeting, New York, NY, USA, 17-22 November 1974; pp. 57-58.

25. Atif, M.; Al-Sulaiman, F.A. Development of a mathematical model for optimizing a heliostat field layout using differential evolution method. Int. J. Energy Res. 2015, 39, 1241-1255. [CrossRef]

26. Saghafifar, M.; Gadalla, M. Thermo-economic analysis of air bottoming cycle hybridization using heliostat field collector: A comparative analysis. Energy 2016, 112, 698-714. [CrossRef]

27. Duffie, J.A.; Beckman, W.A. Solar Engineering of Thermal Processes, 4th ed.; Wiley: Hoboken, NJ, USA, 2013.

28. Collado, F.J. Design of solar tower plants heliostat by heliostat: The shadowing and blocking factor. In Proceedings of the Solarpaces 2011, Granada, Spain, 20-23 Septmeber 2011.

29. Sassi, G. Some notes on shadow and blockage effects. Sol. Energy 1983, 31, 331-333. [CrossRef]

30. Wagner, M.J. Simulation and Predictive Performance Modeling of Utility-Scale Central Receiver System Power Plants; University of Wisconsin: Madison, WI, USA, 2008.

31. Saghafifar, M.; Gadalla, M. Thermo-economic optimization of hybrid solar Maisotsenko bottoming cycles using heliostat field collector: Comparative analysis. Appl. Energy 2017, 190, 686-702. [CrossRef]

32. Modi, A.; Kærn, M.R.; Andreasen, J.G.; Haglind, F. Thermoeconomic optimization of a Kalina cycle for a central receiver concentrating solar power plant. Energy Convers. Manag. 2016, 115, 276-287. [CrossRef]

33. Yu, S.; Zhang, J.; Zheng, S.; Sun, H. Provincial carbon intensity abatement potential estimation in China: A PSO-GA-optimized multi-factor environmental learning curve method. Energy Policy 2015, 77, 46-55. [CrossRef]

34. Klein, S.A. Calculation of monthly average insolation on tilted surfaces. Sol. Energy 1977, 19, 325-329. [CrossRef]

35. Pfahl, A.; Coventry, J.; Röger, M.; Wolfertstetter, F.; Vásquez-Arango, J.F.; Gross, F.; Arjomandi, M.; Schwarzbözl, P.; Geiger, M.; Liedke, P. Progress in heliostat development. Sol. Energy 2017, 152, 3-37. [CrossRef]

(C) 2017 by the authors. Licensee MDPI, Basel, Switzerland. This article is an open access article distributed under the terms and conditions of the Creative Commons Attribution (CC BY) license (http:/ / creativecommons.org/licenses/by/4.0/). 